LBC 87.6

\title{
TRANSFORMATION OF RELIGIOUS COMMUNICATION UNDER THE INFLUENCE OF THE COVID-19 PANDEMIC ${ }^{1}$
}

\author{
Dmitriy A. Chernichkin \\ Astrakhan State University, Astrakhan, Russian Federation
}

\begin{abstract}
The article analyzes the transformation of forms of religious communication against the background of the spread of SARS-CoV-2, the virus, that is responsible for the COVID-19 pandemic. Thanks to the advanced opportunities offered by the virtual space, various religious organizations and individual leaders have the opportunity to acquaint all users with their religious doctrines. But if in ordinary times the virtual religious space often functioned as an "addition" to the real religious space, then in the context of the coronavirus pandemic, it became almost the main channel for broadcasting religious teachings and ideas. In this regard, the capabilities of the virtual environment made it possible to search and experiment. For some people this can lead to a deeper understanding of their religious traditions and practices, while for others it can open up completely new ways of worshiping God, generating a variety of new ideas and trends. The closure of prayer facilities during the coronavirus pandemic has forced most religious institutions around the world to communicate with their followers online, and most of the self-isolated believers have also turned to virtual space in order not to interrupt their religious practices. By itself, virtual religious activity is not a new phenomenon, but in a crisis situation it has become an adequate substitute for real religious activity, making it possible to maintain the epidemiological situation and curb the outflow of the flock, adjusting their religious rituals to the new conditions. On the example of some religious institutions operating on the territory of Russia, it was revealed that during the period of restrictive measures in the country, some forms of religion have undergone significant changes and accelerated digitalization.
\end{abstract}

Key words: religion, religious communication, virtual space, Internet, COVID-19, transformation.

Citation. Chernichkin D.A. Transformation of Religious Communication Under the Influence of the COVID-19 Pandemic. Logos et Praxis, 2021, vol. 20, no. 2, pp. 56-64. (in Russian). DOI: https://doi.org/10.15688/lp.jvolsu.2021.2.7

УДК 130.2

ББК 87.6

ТРАНСФОРМАЦИЯ РЕЛИГИОЗНОЙ КОММУНИКАЦИИ ПОД ВЛИЯНИЕМ ПАНДЕМИИ COVID-19 ${ }^{1}$

\author{
Дмитрий Алексеевич Черничкин \\ Астраханский государственный университет, г. Астрахань, Российская Федерация
}

\begin{abstract}
Аннотация. Статья посвящена анализу трансформации форм религиозной коммуникации на фоне распространения SARS-CoV-2 - вируса, ответственного за пандемию COVID-19. Благодаря расширенным возможностям, которые предлагаются виртуальным пространством, различные религиозные организации и отдельные лидеры получают возможность познакомить всех пользователей со своими религиозными доктринами. Но если в обычное время виртуальное религиозное пространство функционировало зачастую как «дополнение» к реальному религиозному пространству, то в условиях пандемии коронавирусной инфекции оно стало чуть ли не основным каналом трансляции религиозных учений и идей. В связи с этим возможности виртуальной среды позволили искать и экспериментировать. Для некоторых это может привести к более глубокому пониманию их религиозных традиций и практик, а для других это может открывать совершенно новые способы поклонения Богу, порождая разнообразие новых идей и течений. Закрытие молитвенных 巳ि сооружений во время пандемии коронавирусной инфекции вынудило большинство религиозных институ(?) тов по всему миру общаться со своими последователями онлайн, а многие верующие, находящиеся на
\end{abstract}


самоизоляции, также обратились к виртуальному пространству для того, чтобы не прерывать свои религиозные практики. Сама по себе виртуальная религиозная деятельность - явление не новое, но в условиях кризисной ситуации она стала адекватной заменой реальной, позволив поддержать эпидемиологическую обстановку на нормальном уровне и сдержать отток паствы, подстроив свои религиозные обряды под новые условия. На примере некоторых религиозных институтов, действующих на территории России, было выявлено, что за период действия ограничительных мер в стране некоторые формы вероисповедания подверглись значительным изменениям и ускоренной цифровизации.

Ключевые слова: религия, религиозная коммуникация, виртуальное пространство, Интернет, COVID-19, трансформация.

Цитирование. Черничкин Д. А. Трансформация религиозной коммуникации под влиянием пандемии COVID-19// Logos et Praxis. - 2021. - T. 20, № 2. - C. 56-64. - DOI: https://doi.org/10.15688/lp.jvolsu.2021.2.7

\section{Введение}

Мировое виртуальное пространство порождает множество локальных подпространств со своими особенностями. Одним из таких пространств является религиозное, постепенно оказывающее все большее влияние и на российского пользователя. Оно формируется как официальными ресурсами основных религиозных институтов (христианство, ислам, буддизм), аккаунтами и сообществами в социальных сетях, тематическими блогами и форумами, так и возникающими в виртуальном пространстве новыми религиозными институциями и онлайн-играми с религиозным контентом. Так же как и реальное религиозное пространство, оно подвергается внешним воздействиям и, по сути, является сложной виртуальной проекцией реального социума. В повседневной экзистенциальной ситуации такие подпространства могут функционировать как нишевые и малоизвестные широкому пользователю. Однако в случае возникновения экстренных ситуаций, таких как пандемия, экологические катастрофы, масштабные экономические кризисы, являющихся одновременно и вызовом, и угрозой всему человечеству - именно религиозный сегмент виртуального пространства, в основе которого лежит фактор веры и спасения, в той или иной форме подкрепленный современными медиатехнологиями, становится важнейшим рычагом влияния на миллионы пользователей. Он аккумулирует в себе все мировоззренческие и социальные проблемы, обостряемые кризисной ситуацией. Вечная проблема теодицеи осмысливается на новом уровне воздаяния за глобальные грехи всего человечества. Разворачивающаяся на наших глазах ситуация с пандемией COVID-19 как в России, так и во всем мире дает возможность перейти от общих гипотез и теорий к конкретному анализу реакции нтернет-пространства на данную ситуацию.

Репрезентацию большинства религиозных объединений в виртуальном пространстве можно считать одним из трендов современной духовной жизни нашей страны. Специфика виртуального религиозного пространства России была описана в нашей предыдущей работе [Романова и др. 2019]. Можно сказать, что российское религиозное виртуальноепространство обладает целым рядом особенностей:

- ограничено в использовании наличием русскоязычного и церковнославянского контента, что объясняется преобладанием русскоязычных пользователей;

- используется преимущественно молодежной аудиторией, что, предположительно, связано с недостаточным овладением новыми технологиями старшим поколением (от 50 лет) [Жизнь без... web];

- имеет сходство по структуре с обычными виртуальными социальными сетями по нескольким параметрам: массовость потребления (большое количество подписчиков), коммерциализация виртуального продукта (практически на каждом сайте и в мобильном приложении существует система пожертвований на развитие проектов), а также серийность (новые приложения религиозного содержания появляются с определенной периодичностью (каждую неделю) и часто обновляются.

Благодаря расширенным возможностям, которые предлагаются виртуальным пространством, различные религиозные организации и отдельные лидеры получают возможность познакомить всех пользователей со сво- 
ими доктринами. В связи с этим отпадает необходимость посещения молитвенных домов и визитов к пастырям. В данном аспекте можно согласиться с высказыванием Е.О. Гаврилова о том, что «...интернет стал средством укрепления религиозной идентичности, но в тоже время приводит к ее размыванию» [Гаврилов $2014,178]$. Но если в обычное время виртуальное религиозное пространство России функционировало как «дополнение» к реальному религиозному пространству, то в ситуации с пандемией COVID-19 оно стало чуть ли не основным каналом трансляции религиозных учений и идей.

Позиция представителей религиозных институтов по всему миру в данной ситуации тоже была неоднозначной. В самом начале эпидемии призывы отдельных священнослужителей лечить болезнь молитвой в религиозных сооружениях и с помощью ритуалов дестабилизировали эпидемиологическую ситуацию не только в ряде российских регионов, но и по всему миру. Одновременно взвешенные советы руководства конфессиональных сообществ спасли многих от этого необдуманного шага. Поэтому в рамках данной работы нами будет проанализирована трансформация форм религиозной коммуникации на фоне распространения SARS-CoV-2 - вируса, ответственного за пандемию COVID-19.

\section{Обзор литературы}

Активно растущая популярность Интернета способствовала созданию в 90-е гг. XX в. особого научного направления, в рамках которого разрабатывались новые методы изучения религии в интернет-пространстве. Проблематика, связанная с переходом религии в виртуальное пространство, достаточно хорошо представлена в научной литературе. За рубежом фундаментальная работа по исследованию виртуального религиозного пространства ведется уже более 25 лет [Rheingold 1993; Hoover, Lundby 1997; Campbell 2010; Cheruvallil, Shakkour 2015]. Вариант структурирования виртуального религиозного пространства (онлайн-религия) подробно описан в работах К. Хэлланда, который предложил собственный теоретический подход для классификации религиозных сообществ в Интер- нете [Helland 2005; Helland 2007]. Исследованиям религиозной активности пользователей в онлайн пространстве также посвящено множество работ Х. Кэмпбэлл [Campbell 2010; Campbell 2012]. В течение последних трех десятилетий исследователи стремились тщательнее изучить виртуальные религиозные сообщества и их деятельность в пространстве сети Интернет, чтобы проследить, какие аспекты традиционной религиозной практики действительно могут быть переведены в онлайн-пространство и в какой степени религия трансформируется по мере ее адаптации к новым цифровым технологиям [Hojsgaard, Warburg 2005; Campbell, Lovheim 2011].

В отечественной науке этот вопрос рассматривался междисциплинарно. Среди основной массы исследователей хотелось бы выделить работы Е.А. Островской [Островская 2018; Островская 2019], Т.П. Минченко [Минченко 2012], О.К. Михельсон [Михельсон 2018] и др. В рамках анализа и определения специфики виртуального религиозного пространства российскими исследователями рассматривались особенности взаимодействия религиозных институтов и интернет-пространства [Абрамов, Савенкова 2019], изучался феномен онлайн-паломничества в сети Интернет, основываясь на социологическом подходе изучения религии [Павличенко 2018]; выявлялась роль Интернета в формировании уровня религиозности [Тартыгашева 2018], а также анализировались структурные единицы наблюдения религиозной исповеди на платформе видеохостинга YouTube [Алексеева 2019]. Состоянию религиозных общин в условиях различных кризисных ситуаций (экономических, политических, социальных и др.) также посвящено достаточное количество зарубежных научных работ [Trueman, Gould 2016; Wildman et al. 2020; Alyanak 2020; AbdulGafar 2019]. Однако практически нет отечественных исследований, посвященных трансформации религиозных сетей под влиянием различных кризисных ситуаций.

\section{Состояние религиозных институтов во время пандемии}

Закрытие молитвенных сооружений во время пандемии коронавирусной инфекции 
вынудило большинство религиозных институтов действовать по-новому: духовные службы и общение с паствой были быстро и эффективно переведены в пространство сети Интернет. Многие церкви переориентировали свои оффлайн мероприятия под новые условия во избежание оттока паствы: обряды и молитвы, образовательные курсы, послания, проповеди, концерты религиозной музыки, ответы на вопросы прихожан и т. п. Стоит отметить, что религиозная деятельность, перенесенная в виртуальную среду, - явление не новое. Современное религиоведение исследовало эту тему с разных точек зрения и в разных контекстах: ритуальная трансформация [Baesler, Chen 2013], виртуальные храмы [Cowan 2005], онлайн-религиозные сообщества [Hutchings 2011] и т. д.

Однако перенос религиозной деятельности в виртуальное пространство в качестве «прагматического ответа на культурные изменения» [Campbell 2020] некоторыми исследователями воспринимается довольно негативно [Bare 2020], хотя рост религиозного обмена посредством виртуального пространства очевиден. Согласно последнему отчету Google, одной из наиболее популярных молитв в их поисковом запросе в 2020 г. была «молитва о коронавирусе», в которой верующие просят у Бога защиты от болезни COVID-19, силы сопротивляться, а также благодарят за усилия медицинских работников [Bentzen 2020]. В Русской православной церкви был утвержден текст подобной молитвы «от вредоносного поветрия» на церковнославянском языке. А на основании результатов социологического исследования агенства «Pew Research Center», более $50 \%$ опрошенных отметили, что активно молились о прекращении распространения коронавирусной инфекции, причем положительных ответов пожилых людей было больше, чем положительных ответов молодежи; 57 \% процентов тех, кто заявляет о посещении религиозных служб, как правило, не реже одного или двух раз в месяц, сказали, что они смотрели трансляции религиозных служб в сети Интернет или по телевизору [Most Americans... web].

Режим локдауна во многих странах побудил большинство верующих обратиться к виртуальному пространству, чтобы продол- жить богослужение и не прерывать свои религиозные практики. Но, в свою очередь, виртуальное пространство дало пользователям возможность познакомиться с другими формами поклонения, литургическими практиками и проповедями, к которым они обычно не привыкли. Виртуальная среда создала возможность искать и экспериментировать. Для некоторых это может привести к более глубокому пониманию их религиозных традиций и практик, а для других это может открывать совершенно новые способы поклонения Богу, порождая разнообразие новых идей и течений. Английский исследователь Ф. Поттер, взяв за основу концепцию «общества потребления», полагает, что «каждый посетитель церкви - в своем роде потребитель. Он выбирает, где и когда поклоняться, какой религии придерживаться и какого священника он хочет посетить на воскресной службе» [Potter 2015, 47]. Пандемия COVID-19 расширила возможности потребительского выбора: прихожане теперь могут посмотреть проповедь любого религиозного деятеля, следовать за тем, кто им нравится, и не ограничиваться одной религиозной принадлежностью на всю жизнь.

Новые условия стимулировали необходимость в присоединении к виртуальному сообществу. Теперь многие религиозные объединения продолжили свои ежедневные собрания и мероприятия (изучение Библии, Корана, Торы, литургии, собрания молодежных религиозных движений, консультирование прихожан и даже собрания руководства религиозных институтов), которые осуществляются с использованием платформ Zoom, Google, Discord, Instagram, Hangouts и других подобных средств.

\section{Примеры трансформаций форм религиозной коммуникации}

Возможность летального исхода от во3действия нового вируса привела к необходимости изменить свой уклад жизни, соблюдая социальное дистанцирование и исключая ряд форм социального взаимодействия, которые требуют непосредственного физического контакта. Такие меры безопасности сказываются на религиозном сознании, культовой и обрядовой деятельности. Оказавшись в услови- 
ях самоизоляции, человек получает, по мнению Ю.В. Гавриловой и М.А. Жиронкиной, «возможность соприкоснуться со своим внутренним миром, задуматься о себе и своей жизни, и порой люди сталкиваются с чем-то, к чему еще не готовы» [Гаврилова, Жиронкина 2020, 39]. Многим верующим пришлось молиться вне стен молитвенного сооружения, в непривычной обстановке, дома, где нет иногда определенных икон и образов, к которым направлена молитва; отказаться от совершения ряда культовых действий, сопровождающих молитву, ограничить беседы со священнослужителями и т. д.

Выходом из сложившейся ситуации стали возможности сети Интернет. Следует отметить, что наиболее быстро подстроились под новые условия протестантские деноминации, которые на протяжении нескольких лет практиковали еженедельные служения и молитвы в онлайн-пространтстве в целях донесения информации до тех, кто не может присутствовать на службах по причине болезней. Для них онлайн-проповеди и чтение Библии посредством видеосвязи - это не компромисс, а обычная практика. А некоторые обряды в экстренных случаях протестанты могут совершать и без священника. Так, к примеру, в октябре 2020 г. во время онлайн-встречи Российского объединения союза христиан веры евангельской (РОСХВЕ) начальствующим епископом было объявлено, что теперь в экстренных случаях пятидесятники-миряне могут совершать таинства крещения и причастия самостоятельно, а священники - дистанционно, в том числе венчать онлайн: «Конечно, лучще, когда все это происходит вжсивую, но если вдруг возникает пандемия или другие препятствия, мы мгновенно можем уйти в онлайн» [Пятидесятники в России... web].

Русская православная церковь также переориентировала часть своей религиозной деятельности в онлайн-пространство. Казанский священник А. Русакевич, известный пользователям социальный сетей как «Позитивный батюшка», в течение всего периода самоизоляции на территории нашей страны вел ежедневные онлайн-службы из стен храма Казанской иконы Божией матери в Твери через приложение Instagram. Впрочем, подобный вид богослужения священник практику- ет с 2018 г. [Позитивный батюшка web]. В частности посредством своей страницы в социальной сети Instagram он принимает записки на богослужение от мирян, по просьбе прихожан ставит свечки в храме, а также осуществляет причастие через видеосвязь. Так как начало пандемии совпало с празднованием Пасхи, на время проведения праздника священник призывал православных христиан оставаться дома и предлагал освятить вербу и куличи в домашних условиях.

Наряду с другими конфессиями духовным управлением мусульман в РФ были также предприняты действия по реагированию на вызовы, связанные с пандемией. Например, в Москве праздник Ураза-Байрам, который проводится в честь окончания священного месяца Рамадан, прошел без ежегодной массовой молитвы у Соборной мечети. На ней присутствовали только сотрудники духовного управления и ограниченное число священнослужителей. Духовенство порекомендовало мусульманам проводить омовение и молитву дома, проявить терпеливость и послушность и не принимать гостей на праздники во время пандемии [В Москве... web]. Проведение главной молитвы транслировалось посредством прямых эфиров в различных социальных сетях.

\section{Заключение}

По мере того как кризис религиозной жизни, вызванный пандемией коронавирусной инфекции, продолжается, интересно будет проследить за дальнейшим развитием форм религиозной активности. Усилится ли связь между религией и онлайн-пространством в качестве аутентичной формы поклонения в будущем? Еще неизвестно, смогут ли священнослужители вовлекать верующих в онлайн-богослужение в долгосрочной перспективе, ведь большинство верующих в России - люди старшего и преклонного возраста, которые практически не обладают навыками взаимодействия с современными электронными устройствами. Но одно можно сказать с уверенностью: в результате пандемии COVID-19 формы вероисповедания подверглись значительным изменениям. В данной статье была рассмотрена лишь часть изменений, произошедших в обрядовой деятельности некоторых конфессий во время 
пандемии. Сама по себе виртуальная религиозная деятельность - явление не новое, но в условиях кризисной ситуации она стала адекватной заменой реальной религиозной деятельности, позволив поддержать нормальный уровень эпидемиологической обстановки и сдержать отток паствы, подстроив свои религиозные обряды под новые условия.

\section{ПРИМЕЧАНИЕ}

${ }^{1}$ Исследование выполнено за счет гранта Российского научного фонда (проект № 18-78-10064) «Трансформация механизмов формирования по странсгрессионной модели религиозной идентичности в современном информационном пространстве».

The study was carried out by a grant from the Russian Science Foundation (Project No.18-78-10064) "Transformation of mechanisms of formation of posttransgress model of religious identity in the modern information space".

\section{СПИСОК ЛИТЕРАТУРЫ}

Абрамов, Савенкова 2019-Абрамов Е.Ю., Савенкова И.В. Религия в интернет-пространстве// Аллея науки. 2019. Т. 1, № 5 (32). С. 1023-1025.

Алексеева 2019 - Алексеева Е.А. Исповедь как тема коммуникации на платформе YouTube (на примере православных приходов города Екатеринбурга) // Социология религии в обществе позднего модерна. 2019. Т. 8. С. 77-86.

В Москве... web - В Москве из-за пандемии мусульмане отметят Ураза-байрам дома [Sputnik] // https://tj.sputniknews.ru/russia/20200515/ 1031246279/moscow-pandemia-musuljmaneuraza-bayram-doma.html?utm source=yxnews\& utm_medium $=$ desktop.

Гаврилов 2014 - Гаврилов Е.О. Оцифрованное сакральное: особенности существования религии в интернет-пространстве (по материалам СМИ) // Вестник Кемеровского государственного университета культуры и искусств. 2014. №28. С. 177-183.

Гаврилова, Жиронкина 2020 - Гаврилова Ю.В., Жиронкина М.А. Религии в условиях пандемии COVID-19: опыт России // Общество: философия, история, культура. 2020. № 6 (74). С. $36-40$.

Жизнь без... web - Жизнь без интернета: рай или апокалипсис? // https://wciom.ru/index.php?id= 236\&uid $=9681$.

Минченко 2012 - Минченко Т.П. Религия, новые технологии и свобода совести в постсекулярном мире // Известия Томского политехнического университета. 2012. Т. 321, № 6. С. 147-151.

Михельсон 2018 - Михельсон О.К. Сакрализация популярного. Методологические подходы к исследованию Religion-Like Phenomena в современном религиоведении // Вестник СПбГУ. Философия и конфликтология. 2018. Т. 34, № 1. С. 122-137.

Островская 2018 - Островская Е.А. Интернет-медиатизация исповеди в среде православных сетевых vk.com сообществ // Logos et Praxis. 2018. T. 17, № 3. C. 45-58. DOI: https://doi.org/ 10.15688/lp.jvolsu.2018.3.6.

Островская 2019 - Островская Е.A. Медиатизация православия - это возможно? // Мониторинг общественного мнения: экономические и социальные перемены. 2019. № 5 (153). С. 300-319.

Павличенко 2018 - Павличенко 3.Ю. Паломничество и другие ритуалы в киберпространстве // Религиоведение. 2018. № 1. С. 52-57.

Позитивный батюшка web - Позитивный батюшка [Социальная сеть Instagram] // https://www. instagram.com/pozitivniy_batushka/?igshid=1 kyfms $999093 \mathrm{y}$.

Пятидесятники в России... web-Пятидесятники в Роcсии могут креститься и совершать причастие без священника [РИА новости] // https://ria.ru/ 20201022/protestanty--1581044758.html.

Романова и др. 2019 - Романова А.П., Топчиев М.С., Черничкин Д.А., Дрягалов В.С., Рогов А.В. Влияние виртуального пространства на формирование религиозной идентичности студенческой молодежи (на примере Юга России) // Южно-российский журнал социальных наук. 2019. № 2. С. 99-120.

Тартыгашева 2018 - Тартыгашева Г. Социологические исследования религиозности в сети интернет // Вестник РГГУ. Серия: Философия, социология, искусствоведение. 2018. № 3 (13). C. 92-98.

AbdulGafar 2019 - AbdulGafar O.F. Islam and Disaster Management in Contemporary Times: A PsychoSocio-Spiritual Response // Journal of Religion \& Spirituality in Social Work: Social Thought. 2019. № 38 (3). P. 259-280.

Alyanak 2020 - Alyanak $O$. Faith, Politics and the COVID-19 Pandemic: The Turkish Response // Medical Anthropology. Cross-Cultural Studies in Health and Illness. 2020. Vol. 39, iss. 5. P. 374 375. DOI: $10.1080 / 01459740.2020 .1745482$.

Baesler, Chen 2013 - Baesler J., Chen Y.F. Mapping the Landscape of Digital Petitionary Prayer As Spiritual / Social Support in Mobile, Facebook, and E-mail // Journal of Media and Religion. 2013. Vol. 12 (1). P. 1-15. DOI: 10.1080/ 15348423.2013.760385. 
Bare 2020 - Bare D. How Embodied is "The Body of Christ?" COVID-19 and Christian Corporeality // Religion in Quarantine: The Future of Religion in a Post-Pandemic World. Network for New Media, Religion \& Digital Culture Studies. Texas: Texas A \&M University, 2020. P. 36-38.

Bentzen 2020 - Bentzen J.S. Acts of God? Religiosity and Natural Disasters Across Subnational World Districts // The Economic Journal. 2019. Iss. 129 (622). P. 2295-2321.DOI:10.1093/ej/uez008.

Campbell 2010 - Campbell H. When Religion Meets New Media. L.: Routledge, 2010.

Campbell 2012 - Campbell H. How Religious Communities Negotiate New Media Religiously // Digital Religion, Social Media and Culture: Perspectives, Practices and Futures. N. Y.: Peter Lang, 2012. P. 81-96.

Campbell 2020 - Campbell $H$. Religion Embracing and Resisting Cultural Change in a Time of Social Distancing // Religion in Quarantine: The Future of Religion in a Post-Pandemic World. Network for New Media, Religion \& Digital Culture Studies. Texas: Texas A\&M University, 2020. P. 9-14.

Campbell, Lovheim 2011 - Campbell H., Lovheim M. Rethinking the Online-Offline Connection in Religion Online// Information, Communication \& Society. 2011. № 18. P. 1083-1096.

Cheruvallil, Shakkour 2015-Cheruvallil C., Shakkour S. Digital Methodologies in the Sociology of Religion. L.: Bloomsbury Publishing, 2015.

Cowan 2005 - Cowan D. Online U-Topia: Cyberspace and the Mythology of Placelessness // Journal for the Scientific Study of Religion. 2005. Iss. 44 (3). P. 257-263.DOI:10.1111/j.1468-5906.2005.00284.x.

Helland 2005 - Helland C. Online Religion As Lived Religion Methodological Issues in the Study of Religious Participation on the Internet // Online - Heidelberg Journal of Religions on the Internet. 2005. Vol. 01.1. P. 1-16.

Helland 2007 - Helland C. Diaspora on the Electronic Frontier: Developing Virtual Connections with Sacred Homelands // Journal of ComputerMediated Communication (Special Issue on Religion and the Internet). 2007. № 12. P. 956-976.

Hojsgaard, Warburg 2005 - Hojsgaard M., Warburg W. Religion and Cyberspace. L.: Routledge, 2005.

Hoover, Lundby 1997 - Hoover S.M., Lundby K. Rethinking Media, Religion and Culture. Thousand Oaks: Sage, 1997.

Hutchings 2011 - Hutchings T. Contemporary Religious Community and the Online Church // Information, Communication \& Society. 2011. Iss. 14(8). P. 1118-1135. DOI:10.1080/1369118x. 2011.591410.

Most Americans... web - Most Americans Say Coronavirus Outbreak Has Impacted Their Lives
[Pew Research Center] // https://www. pewsocialtrends.org/2020/03/30/most-americanssay-coronavirus-outbreak-has-impacted-theirlives/?utm_source=link_newsv9\&utmcampaign =item307619\&utmmedium $=$ copy.

Potter 2015 - Potter P. Pioneering a New Future: A Guide to Shaping Change and Changing the Shape of the Church. Rossendale: The Bible Reading Fellowship, 2015.

Rheingold 1993 - Rheingold $H$. The Virtual Community. N. Y.: Harper, 1993.

Trueman, Gould 2016-Trueman L., Gould O.N. The Role of Religion When Crisis Looms: A Church Community at a Crossroads // Journal of Religion, Spirituality \& Aging. 2016. № 29 (1). P. 18-32.

Wildman et al. 2020 - Wildman W.J., Bulbulia J., Sosis R., Schjoedt $U$. Religion and the COVID-19 Pandemic // Religion, Brain \& Behavior. 2020. № 10 (2). P. 115-117.

\section{REFERENCES}

Abramov E.Yu., Savenkova I.V., 2019. Religion in the Internet Space. Alleya nauki, vol. 1, no. 5 (32), pp. 1023-1025.

Alekseeva E.A., 2019. Confession As a Topic of Communication on the YouTube Platform (On the Example of Orthodox Parishes in Yekaterinburg). Sociologiya religii $v$ obshchestve pozdnego moderna, vol. 8, pp. 77-86.

In Moscow, due to the Pandemic, Muslims will Celebrate Eid al-Adha at Home. Sputnik. URL: https://tj.sputniknews.ru/russia/20200515/ 1031246279/moscow-pandemia-musuljmaneuraza-bayram-doma.html?utm_source= yxnews\&utm_medium=desktop.

Gavrilov E.O., 2014. Digitized Sacred: Features of the Existence of Religion in the Internet Space (Based on Media Materials). Vestnik Kemerovskogo gosudarstvennogo universiteta kul'tury $i$ iskusstv, no. 28, pp. 177-183.

Gavrilova Yu.V., Zhironkina M.A., 2020. Religions in the Context of the COVID-19 Pandemic: Russia's Experience. Obshchestvo: filosofiya, istoriya, kul'tura, vol. 6 (74), pp. 36-40.

Life Without the Internet: Heaven or Apocalypse? URL: https://wciom.ru/index.php?id=236\&uid $=9681$.

Minchenko T.P., 2012. Religion, New Technologies and Freedom of Conscience in the Post-Secular World. Izvestiya Tomskogo politekhnicheskogo universiteta, vol. 321, no. 6, pp. 147-151.

Mihel'son O.K., 2018. Sacralization of the Popular. Methodological Approaches to the Study of Religion-Like Phenomena in Modern Religious 
Studies. Vestnik SPbGU. Filosofiya i konfliktologiya, vol. 34, no. 1, pp. 122-137.

Ostrovskaya E.A., 2018. Internet Mediatization of Confession in the Orthodox Social Networking Sight Vk.com. Logos et Praxis, vol. 17, no. 3, pp. 45-58. DOI: https://doi.org/10.15688/lp.jvolsu.2018.3.6.

Ostrovskaya E.A., 2019. Is it Possible to Mediatize Orthodoxy? Monitoring obshchestvennogo mneniya: ekonomicheskie $i$ social'nye peremeny, no. 5 (153), pp. 300-319.

Pavlichenko Z.Yu., 2018. Pilgrimage and Other Rituals in Cyberspace. Religiovedenie, no. 1, pp. 52-57.

The Positive Priest. Social 'naya set' Instagram. URL: https://www.instagram.com/pozitivniy_ batushka/?igshid=1 kyfms999093y.

Pentecostals in Russia Can Be Baptized and Partake of the Sacrament Without a Priest. RIA novosti. URL: https://ria.ru/20201022/protestanty-1581044758.html.

Romanova A.P., Topchiev M.S., Chernichkin D.A., Dryagalov V.S., Rogov A.V., 2019. The Influence of the Virtual Space on the Formation of Religious Identity of Student Youth (On the Example of the South of Russia). South-Russian Journal of Social Sciences, no. 2, pp. 99-120.

Tartygasheva G., 2018. Sociological Research of Religiosity on the Internet. Vestnik RGGU. Seriya: Filosofiya, sociologiya, iskusstvovedenie, no. 3(13), pp. 92-98.

AbdulGafar O.F., 2019. Islam and Disaster Management in Contemporary Times: A Psycho-Socio-Spiritual Response. Journal of Religion \& Spirituality in Social Work: Social Thought, no. 38(3), pp. 259-280.

Alyanak O., 2020. Faith, Politics and the COVID-19 Pandemic: The Turkish Response. Medical Anthropology. Cross-Cultural Studies in Health and Illness, vol. 39, iss. 5, pp. 374-375. DOI: 10.1080/01459740.2020.1745482.

Baesler J., Chen Y.F., 2013. Mapping the Landscape of Digital Petitionary Prayer as Spiritual/Social Support in Mobile, Facebook, and E-mail. Journal of Media and Religion, iss. 12 (1), pp. 1-15. DOI: 10.1080/15348423.2013.760385.

Bare D., 2020. How Embodied is "The Body of Christ?" COVID-19 and Christian Corporeality. Religion in Quarantine: The Future of Religion in a PostPandemic World. Network for New Media, Religion \& Digital Culture Studies. Texas, Texas A\&M University, pp. 36-38.

Bentzen J.S., 2019. Acts of God? Religiosity and Natural Disasters Across Subnational World Districts. The Economic Journal, iss. 129 (622), pp. 22952321. DOI:10.1093/ej/uez008.

Campbell H., 2010. When Religion Meets New Media. London, Routledge Publ.

Campbell H., 2012. How Religious Communities Negotiate New Media Religiously. Digital
Religion, Social Media and Culture. Perspectives, Practices and Futures. New York, Peter Lang Publ., pp. 81-96.

Campbell H., 2020. Religion Embracing and Resisting Cultural Change in a Time of Social Distancing. Religion in Quarantine: The Future of Religion in a Post-Pandemic World. Network for New Media, Religion \& Digital Culture Studies, Texas, Texas A\&M University, pp. 9-14.

Campbell H., Lovheim M., 2011. Rethinking the OnlineOffline Connection in Religion Online. Information, Communication \& Society, no. 18, pp. 1083-1096.

Cheruvallil C., Shakkour S., 2015. Digital Methodologies in the Sociology of Religion. London, Bloomsbury Publishing.

Cowan D., 2005. Online U-Topia: Cyberspace and the Mythology of Placelessness. Journal for the Scientific Study of Religion, iss. 44 (3), pp. 257263. DOI:10.1111/j.1468-5906.2005.00284.x.

Helland C., 2005. Online Religion as Lived Religion Methodological Issues in the Study of Religious Participation on the Internet. Online - Heidelberg journal of religions on the Internet, vol. 01.1, pp. 1-16.

Helland C., 2007. Diaspora on the Electronic Frontier: Developing Virtual Connections with Sacred Homelands. Journal of Computer-Mediated Communication (Special Issue on Religion and the Internet), no. 12, pp. 956-976.

Hojsgaard M., Warburg W., 2005. Religion and Cyberspace. London, Routledge Publ.

Hoover S.M., Lundby K., 1997. Rethinking Media, Religion and Culture. Thousand Oaks, Sage Publ.

Hutchings T., 2011. Contemporary Religious Community and the Online Church. Information, Communication \& Society, iss. 14 (8), pp. 11181135. DOI:10.1080/1369118x.2011.591410.

Most Americans Say Coronavirus Outbreak Has Impacted Their Lives. Pew Research Center. URL: https://www.pewsocialtrends.org/2020/03/ 30/most-americans-say-coronavirus-outbreakhas-impacted-their-lives/?utm_source=link_newsv 9\&utmcampaign=item 307619 \&utmmedium $^{-}=$copy.

Potter P., 2015. Pioneering a New Future: A Guide to Shaping Change and Changing the Shape of the Church. Rossendale, The Bible Reading Fellowship Publ.

Rheingold H., 1993. The Virtual Community. New York, Harper Publ.

Trueman L., Gould O.N., 2016. The Role of Religion When Crisis Looms: A Church Community at a Crossroads. Journal of Religion, Spirituality \& Aging, no. 29 (1), pp. 18-32.

Wildman W.J., Bulbulia J., Sosis R., Schjoedt U., 2020. Religion and the COVID-19 Pandemic. Religion, Brain \& Behavior, no. 10 (2), pp. 115-117. 


\section{ИЗОЛЯЦИЯ В ОТКРЫТОМ ОБЩЕСТВЕ}

\section{Information About the Author}

Dmitriy A. Chernichkin, Postgraduate Student, Department of Cultural Studies, Junior Researcher, Laboratory for the Study of Socio-Political and Cultural Dynamics of the Lower Volga Region and the Caspian Region, Astrakhan State University, Tatishcheva St, 20a, 414056 Astrakhan, Russian Federation, chernichkin95@mail.ru, https://orcid.org/0000-0002-9647-7916

\section{Информация об авторе}

Дмитрий Алексеевич Черничкин, аспирант кафедры культурологии, младший научный сотрудник лаборатории по исследованию социально-политической и культурной динамики региона Нижнего Поволжья и Прикаспия, Астраханский государственный университет, ул. Татищева, 20a, 414056 г. Астрахань, Российская Федерация, chernichkin95@mail.ru, https://orcid.org/0000-0002-9647-7916 